\title{
Erratum to: Eight-Year Experience with Minimally Invasive Cardiothoracic Surgery
}

\author{
Alexander Iribarne $\cdot$ Anna Karpenko $\cdot$ Mark J. Russo • \\ Faisal H. Cheema • Tianna Umann • Mehmet C. Oz • \\ Craig R. Smith $\cdot$ Michael Argenziano
}

Published online: 10 December 2009

(C) Société Internationale de Chirurgie 2009

\section{Erratum to: World J Surg}

DOI 10.1007/s00268-009-0260-7

In the following article, we would like to bring your attention to an incomplete printing of Dr. Cheema's name. It should be listed as Cheema F.H.

The online version of the original article can be found under doi:10.1007/s00268-009-0260-7.

\footnotetext{
A. Iribarne - A. Karpenko - M. J. Russo -

F. H. Cheema - T. Umann - M. C. Oz - C. R. Smith .

M. Argenziano $(\square)$

Division of Cardiothoracic Surgery, Department of Surgery,

College of Physicians and Surgeons, Columbia University

Medical Center, 77 Fort Washington Avenue, Milstein Hospital,

Suite 7-435, New York, NY 10032, USA

e-mail: ma66@columbia.edu
}
A. Iribarne
e-mail: ai2141@ @columbia.edu 